\title{
The influence of D-chiro-inositol and D-myo-inositol in pregnant women with glucose intolerance
}

\author{
DOMENICO DELL'EDERA, FRANCESCA SARLO, ARIANNA ALLEGRETTI, \\ FRANCESCA SIMONE, MARIA GIOVANNA LUPO and ANNUNZIATA ANNA EPIFANIA \\ Unit of Cytogenetic and Molecular Genetics, 'Madonna delle Grazie' Hospital, 75100 Matera, Italy
}

Received April 24, 2017; Accepted May 23, 2017

DOI: 10.3892/br.2017.939

\begin{abstract}
The aim of the present study was to demonstrate that the use of inositol and folic acid from the first trimester of pregnancy, counteracts the onset of gestational diabetes mellitus (GDM) in women at risk, preserving the infants from macrosomia, hypoglycemia and preterm delivery. The authors collected data from the pregnant women at the laboratory (Unit of Cytogenic and Molecular Genetics), from January 2014 to April 2016, all with first trimester fasting plasma glucose $(\mathrm{FPG})>92 \mathrm{mg} / \mathrm{dl}$. A total of 40 women were treated with $250 \mathrm{mg} /$ day D-chiro-inositol, $1.75 \mathrm{~g} / \mathrm{day}$ D-myo-inositol, $12.5 \mathrm{mg} /$ day zinc, $10 \mathrm{mg} /$ day methylsulfonylmethane, $400 \mu \mathrm{g} /$ day 5 -methyltetrahydrofolic acid. The other 43 women (control group) were treated with only $400 \mu \mathrm{g} /$ day folic acid. The primary outcome measure was the incidence of maternal GDM. The secondary outcome measures were the incidence of fetal macrosomia, preterm delivery and neonatal hypoglycemia. At the 24th week of pregnancy, the incidence of maternal GDM was recorded in 18 women in the control group and in 5 women in the treated group [relative risk $(\mathrm{RR})=3.35 ; 95 \%$ confidence interval $(\mathrm{CI})=1.37-8.17 ; \mathrm{P}=0.0028)$. A significant difference was observed between treated and control groups in terms of risk of macrosomia. A total of seven infants in the control group, and two in the treated group, weighed $>4,000 \mathrm{~g}(\mathrm{RR}=5,12$; 95\% CI=1.21-21.68; $\mathrm{P}=0.0099)$. No significant difference was identified between two groups, regarding the other two secondary outcomes, neonatal hypoglycemia $(\mathrm{R} R=4.650$; $95 \% \mathrm{CI}=0.57-38.11 ; \mathrm{P}=0.1086)$ and preterm delivery
\end{abstract}

Correspondence to: Dr Domenico Dell'Edera, Unit of Cytogenetic and Molecular Genetics, 'Madonna delle Grazie' Hospital, Via Montescaglioso, 75100 Matera, Italy

E-mail: domenicodelledera68@gmail.com

Abbreviations: FPG, fasting plasma glucose; GDM, gestational diabetes mellitus; OGTT, oral glucose tolerance test; HbA1c, glycosylated hemoglobin

Key words: D-chiro-inositol, D-myo-inositol, folic acid, fasting blood glucose, gestational diabetes mellitus
( $\mathrm{RR}=1.74 ; 95 \% \mathrm{CI}=0.83-3.66 ; \mathrm{P}=0.1301)$. The current study demonstrated the potential benefit of supplementation with the association of D-chiro-inositol and D-myo-inositol in pregnant 'at risk' women, with first trimester FPG >92 mg/dl, in preventing the onset of maternal GDM and macrosomia in newborns.

\section{Introduction}

Gestational diabetes mellitus (GDM) is defined as "carbohydrate intolerance of variable severity with onset or first recognition during pregnancy' (1). It usually subsides following pregnancy, but also significantly increases a woman's risk of both type 2 diabetes and cardiovascular disease in the postpartum period.

Pregnancy, due to placental hormone action, is characterized by a physiological increase of insulin resistance (IR), which has the aim to promote the use of nutrients by the fetus, especially in the second and third trimesters of pregnancy (2), however, this physiological mechanism could lead to the onset of GDM (3).

The diagnosis of GDM is usually made using an oral glucose tolerance test between 24-28 weeks' gestation and is associated to risks for the fetus, including macrosomia (birth weight $>4,000 \mathrm{~g}$ ) and birth injuries such as shoulder dystocia, or problems in newborns such as neonatal hypoglycemia, respiratory distress syndrome, childhood obesity, and for the mother, such as caesarean delivery, hypertensive disorders and an increased risk of developing type 2 diabetes later in life (4).

Both pharmacological (oral antidiabetic drugs or insulin) and non-pharmacological (dietary and lifestyle counseling) interventions are used to treat GDM, with the aim to control hyperglycemia.

Historically, insulin has been the therapeutic agent of choice for controlling hyperglycemia in pregnant women. However, difficulty in medication administration with multiple daily injections, potential for hypoglycemia and increase in appetite and weight make this therapeutic option cumbersome for many pregnant patients, often presenting suboptimal compliance (5).

Moreover, hypoglycemia occurs in $\sim 71 \%$ of women who take insulin at some time during their pregnancy (5). The use of oral hypoglycemic drugs has become an attractive option in pregnancy; among these, the authors focused metformin. 
Metformin acts by decreasing hepatic glucose output by inhibition of gluconeogenesis and enhances peripheral glucose uptake in the muscles and adipose tissues. It also decreases intestinal glucose absorption, reduces both fasting and postprandial plasma glucose and increases insulin sensitivity (5).

Oral hypoglycemics and/or insulin therapy are recommended for women with GDM who are unable to maintain glycemic control with dietary and lifestyle interventions alone (6).

However, the use of hypoglycemic drugs has reported adverse effects as the potential risks of neonatal hypoglycemia and teratogenicity associated with placental transfer to the fetus $(7,8)$.

There is a need for safe, simple and efficacious interventions to prevent the development of GDM. In order to prevent perinatal complications of mothers and infants mentioned above, the goal of glycemic control during pregnancy should be to bring plasma glucose level as close to normal as possible without development of hypoglycemia (9).

Inositol (1,2,3,4,5,6-hexahydroxycyclohexane) is a cyclitol naturally present in animal and plant cells, either in its free form or as a bound-component of phospholipids or inositol derivatives.

It exists under nine stereoisomeric forms and myo-inositol is the predominant isomeric form, it is broadly distributed in eukaryotic tissues and cells in which acts as second messenger, regulating the activities of several hormones such as follicle stimulating hormone, thyroid stimulating hormone and insulin (10).

Whereas the intracellular inositol pool is $>99 \%$ constituted by myo-inositol in most tissues, significant differences have been recorded in the concentration of myo-inositol and D-chiro-inositol, another important stereoisomer, in fat, muscle and liver (10). This different distribution reflects the distinct functions that likely the two isomers are playing in those tissues, and their respective proportions are actively maintained as myo-inositol is enzymatically transformed into D-chiro-inositol through a NAD, NADH-dependent epimerase, according to tissue requirement, the enzymatic reaction stimulated by insulin (10).

Abnormalities in myo-inositol and in D-chiro-inositol metabolism have been involved in the development of several diseases and in particular in the development of IR and diabetic complications $(11,12)$.

The objective of the present study was to demonstrate that, in the preconceptional period, D-chiro-inositol and D-myo-inositol first of all prevent the onset of GDM in women at risk, and protect infants from macrosomia, preterm delivery and hypoglycemia.

\section{Materials and methods}

Patient data. From January 2014 to April 2016, the authors collected data derived from 93 women in pregnancy arrived in the laboratory (Laboratory of Cytogenetic and Molecular Genetics) for the first trimester screening for aneuploidy by using nuchal translucency sonography and analysis of proteins and placental hormones (bi-test or combined test). A statement of informed consent was signed by all women according to principles of Helsinki Declaration. These
Table I. Baseline parameters of both groups.

\begin{tabular}{lccc}
\hline & $\begin{array}{c}\text { Treated group } \\
(\mathrm{n}=40)\end{array}$ & $\begin{array}{c}\text { Control group } \\
(\mathrm{n}=43)\end{array}$ & P-value \\
\hline Age $($ years $)$ & $32.50 \pm 3.56$ & $32.34 \pm 3.78$ & $\mathrm{~ns}$ \\
$\mathrm{BMI}\left(\mathrm{kg} / \mathrm{m}^{2}\right)$ & $25.62 \pm 4.03$ & $26.86 \pm 3.12$ & $\mathrm{~ns}$ \\
$\mathrm{SBP}(\mathrm{mmHg})$ & $118.50 \pm 12.02$ & $119.56 \pm 10.20$ & $\mathrm{~ns}$ \\
$\mathrm{DBP}(\mathrm{mmHg})$ & $68.46 \pm 8.78$ & $67.32 \pm 8.52$ & $\mathrm{~ns}$ \\
$\mathrm{FBG}(\mathrm{mg} / \mathrm{dl})$ & $85.78 \pm 7.13$ & $85.20 \pm 7.35$ & $\mathrm{~ns}$ \\
$\mathrm{HbA} 1 \mathrm{c}(\mathrm{mmol} / \mathrm{mol})$ & $31.85 \pm 8.25$ & $31.55 \pm 7.80$ & $\mathrm{~ns}$ \\
$\mathrm{Hb}(\mathrm{g} / \mathrm{dl})$ & $13.10 \pm 1.52$ & $12.87 \pm 1.67$ & $\mathrm{~ns}$ \\
\hline
\end{tabular}

Data are presented as mean \pm standard deviation. $\mathrm{P}<0.05$ was considered to indicate a statistically significant difference. Ns, no significant; BMI, body mass index; SBP, systolic blood pressure; DBP, diastolic blood pressure; FBG, fasting blood glucose; HbA1c, glycated hemoglobin; Hb, hemoglobin.

women had a fasting plasma glucose value in the first trimester $>92 \mathrm{mg} / \mathrm{dl}$.

A total of 40 women were treated with $250 \mathrm{mg} /$ day of D-chiro-inositol, $1.75 \mathrm{~g} /$ day D-myo-inositol, $12.5 \mathrm{mg} /$ day zinc, $10 \mathrm{mg} /$ day methylsulfonylmethane and $400 \mathrm{mg}$ /day 5-methyltetrahydrofolic acid. The other 43 women (control group) were treated with only $400 \mathrm{mg} /$ day of folic acid.

The primary outcome measure was the incidence of maternal GDM. The secondary outcome measures were the requirement of maternal insulin therapy, the incidence of fetal macrosomia and neonatal hypoglycemia.

The inclusion criteria were as follows: Preconceptional (1 month before conception) supplementation with folic acid, no previous diabetes mellitus, Caucasian women with singleton pregnancy without GDM, whose first degree relative was not affected by type- 2 diabetes and hypertension; whose BMI $<30 \mathrm{~kg} / \mathrm{m}^{2}$; an elevated fasting glucose (glycemia $\geq 5.1 \mathrm{mmol} / 1$ or $92 \mathrm{mg} / \mathrm{dl}$ and $\leq 7.0 \mathrm{mmol} / 1$ or $126 \mathrm{mg} / \mathrm{dl}$ ) according to IADPSG Guidelines (13) and hypocaloric and low-glycemic index diet according to standard care.

The exclusion criteria were as following: BMI $\geq 30 \mathrm{~kg} / \mathrm{m}^{2}$, previous GDM, pre-gestational diabetes, first trimester glycosuria, first degree relative affected by type 2 diabetes or hypertension, fasting plasma glucose $<126 \mathrm{mg} / \mathrm{dl}$ or random glycaemia $<200 \mathrm{mg} / \mathrm{dl}$, hemoglobin $(\mathrm{Hb})<10 \mathrm{~g} / \mathrm{dl}$, carrier of thalassemic trait, sickle cell anemia, twin pregnancy, therapy with corticoids, not caucasian or with polycystic ovary syndrome.

Statistical analysis. Statistical analysis was carried out with SPSS software (version, 17; SPSS, Inc., Chicago, IL, USA). Data are expressed as means \pm standard deviation for categorical variables. The means of independent groups were compared using Student's t test after checking for normal distribution. For analysis of paired data, Student's t-test was also used.

The relative risk (RR) with $95 \%$ confidence intervals (CIs) was calculated for non-parametric parameters. $\mathrm{P}<0.05$ was considered to indicate a statistically significant difference. 
Table II. Incidence of primary and secondary outcomes in treated and control groups following the 24th week of pregnancy.

\begin{tabular}{lcccr}
\hline Outcome & Treated group $(\mathrm{n}=40)$ & Control group $(\mathrm{n}=43)$ & RR $(95 \% \mathrm{CI})$ & P-value \\
\hline $\begin{array}{l}\text { Primary outcome } \\
\text { Onset of GDM }\end{array}$ & 5 & 18 & $3.35(1.37-8.17)$ & 0.0028 \\
Secondary outcome & & & & \\
Macrosomia $(>4 \mathrm{~kg})$ & 2 & 11 & $5.12(1.21-21.68)$ & 0.0099 \\
Neonatal hypoglycemia & 1 & 5 & $4.65(0.57-38.11)$ & 0.1086 \\
Preterm delivery & 8 & 15 & $1.74(0.83-3.66)$ & 0.1301
\end{tabular}

RR, relative risk; $\mathrm{CI}$, confidence interval. $\mathrm{P}<0.05$ was considered to indicate a statistically significant difference.

\section{Results}

The study involved data from 92 women, however were excluded: Seven women due to $\mathrm{Hb}$ value $<10 \mathrm{~g} / \mathrm{dl}$ and two due to midtrimester miscarriage. Therefore, the authors collected data from 40 women treated with inositol and folic acid (treated group) and from 43 women with supplementation only with folic acid (control group).

No statistical difference was identified, at baseline, between two groups, in terms of age, BMI, systolic and diastolic blood pressure, FBG, HbAlc and $\mathrm{Hb}$ values (Table I).

Following the 24th week of pregnancy, the incidence of maternal GDM was recorded in 18 women in the control group and in 5 women in the treated group ( $R R=3.35$; 95\% CI=1.37-8.17; $\mathrm{P}=0.0028$ ) (Table II). A significant difference was observed between treated and control groups for the risk of macrosomia; seven infants, in the control group, weighed $>4 \mathrm{~kg}$ and two in the treated group $(\mathrm{RR}=5.12 ; 95 \%$ $\mathrm{CI}=1.21-21.68 ; \mathrm{P}=0,0099)$ (Table II).

No significant difference was observed between two groups, regarding the other two secondary outcomes, neonatal hypoglycemia $(\mathrm{RR}=4.650 ; 95 \% \mathrm{CI}=0.57-38.11 ; \mathrm{P}=0.1086)$ and preterm delivery $(\mathrm{RR}=1.74 ; 95 \% \mathrm{CI}=0.83-3.66 ; \mathrm{P}=0,1301)$.

\section{Discussion}

To date, the treatment options currently available to women with GDM are restricted to subcutaneous insulin therapy however, it may present side effects such as hypoglycemia, increased weight gain during pregnancy, which are themselves linked to adverse pregnancy outcomes, and it requires self-injection (14). Metformin is an effective treatment for GDM and other disorders of IR, but often requires additional treatment with insulin in order to maintain adequate glycemic control (14). Furthermore, it is also known to cross the placenta, and the long-term effects on the unborn child are still unknown (15).

For these reasons, much research is dedicated to the development of alternative treatments (14).

Due to its role as a second messenger in the signal transduction processes, several clinical trials (10-16) have suggested a beneficial effect of inositol (myo- or chiro-) supplementation in improving ovarian function, hormone status and glucose homeostasis, with no reported side effects, For this reason, it may potentially be used on a population-wide level.
Moreover, Corrado et al (17) demonstrated a greater decrease in markers for IR among gestational diabetic women with dietary supplementation randomly exposed to myo-inositol plus folic acid as compared with folic acid alone.

The current results matched with those obtained by D'Anna et al (12), in their study highlighting a reduction in terms of incidence of GDM and fetal macrosomia, in women with only family history of type 2 diabetes treated with $4 \mathrm{~g}$ myo-inositol $+400 \mathrm{mg} /$ day compared to the placebo group, who were only treated with folic acid $400 \mathrm{mg} /$ day.

Moreover, according to Matarrelli et al (18), the finding that maternal/fetal/neonatal GDM in women at high risk, was well controlled in the myo-inositol group, was confirmed.

Therefore, the present study demonstrates that the supplementation with D-chiro-inositol and D-myo-inositol gives good control of maternal glycemia and good perinatal outcomes, and further studies are needed to compare these with those offered by the treatment with insulin or oral hypoglycemic drugs.

Despite the limited number of study population, the authors proposed that, in order to prevent the onset of GDM, the dosage of $250 \mathrm{mg} / \mathrm{day} \mathrm{D}$-chiro-inositol and of $200 \mathrm{mg} / \mathrm{day}$ D-myo-inositol may be an optimal dosage in pregnant women at risk for GDM, with first trimester FBG $>92 \mathrm{mg} / \mathrm{dl}$, and could represent a possible alternative to oral antidiabetic drugs, when their use is not possible (for example in metformin intolerance or drug contraindications).

However, further studies are required to explore the optimal dose of inositol supplementation, and to establish long-term safety, involving a larger number of patients from different ethnicities and with different risk factors for GDM.

In order to prevent perinatal complication of mothers and infants, and to avoid risk of adverse outcomes in pregnancy and in the long term, there is a urgent need to reinforce preconceptional care. The current study demonstrates the potential benefit of supplementation with the association of D-chiro-inositol and D-myo-inositol in pregnant 'at risk' women, with first trimester FBG of $>92 \mathrm{mg} / \mathrm{dl}$, in preventing the onset of maternal GDM and macrosomia in newborns.

\section{Acknowledgements}

The authors would like to thank 'Associazione Gian Franco Lupo-Un Sorriso Alla Vita' (ONLUS: non-profit organization of social utility). 


\section{References}

1. Vedavathi KJ, Swamy RM, Kanavi RS, Venkatesh G and Veerananna HB: Influence of gestational diabetes mellitus on fetal growth parameters. Int J Biol Med Res 2: 832-834, 2011.

2. Homko C, Sivan E, Chen X, Reece EA and Boden G: Insulin secretion during and after pregnancy in patients with gestational diabetes mellitus. J Clin Endocrinol Metab 86: 568-573, 2001.

3. Buchanan TA, Xiang AH, Peters RK, Kjos SL, Berkowitz K, Marroquin A, Goico J, Ochoa C and Azen SP: Response of pancreatic beta-cells to improved insulin sensitivity in women at high risk for type 2 diabetes. Diabetes 49: 782-788, 2000.

4. Giugliano E, Cagnazzo E, Giugliano B, Caserta D, Moscarini M and Marci R: The Prevention of Gestational Diabetes. J Diabetes Metab 4: 286, 2013.

5. Magon N and Seshiah V: Gestational diabetes mellitus: Non-insulin management. Indian J Endocrinol Metab 15: 284-293, 2011.

6. Brown J, Crawford TJ, Alsweiler J and Crowther CA: Dietary supplementation with myo-inositol in women during pregnancy for treating gestational diabetes. Cochrane Database Syst Rev 9 CD012048, 2016.

7. Hellmuth E, Damm P and Mølsted-Pedersen L: Oral hypoglycaemic agents in 118 diabetic pregnancies. Diabet Med 17: $507-511,2000$

8. Sutherland HW, Bewsher PD, Cormack JD, Hughes CR, Reid A, Russell G and Stowers JM: Effect of moderate dosage of chlorpropamide in pregnancy on fetal outcome. Arch Dis Child 49: 283-291, 1974.

9. Hashimoto K and Koga M: Indicators of glycemic control in patients with gestational diabetes mellitus and pregnant women with diabetes mellitus. World J Diabetes 6: 1045-1056, 2015.

10. Facchinetti F, Bizzarri M, Benvenga S, D'Anna R, Lanzone A, Soulage C, Di Renzo GC, Hod M, Cavalli P, Chiu TT, et al: Results from the International Consensus Conference on myo-inositol and d-chiro-inositol in obstetrics and gynecology: The link between metabolic syndrome and PCOS. Eur J Obstet Gynecol Reprod Biol 195: 72-76, 2015.
11. Kawa JM, Przybylski R and Taylor CG: Urinary chiro-inositol and $m y o$-inositol excretion is elevated in the diabetic $\mathrm{db} / \mathrm{db}$ mouse and streptozotocin diabetic rat. Exp Biol Med (Maywood) 228: 907-914, 2003.

12. D'Anna R, Scilipoti A, Giordano D, Caruso C, Cannata ML, Interdonato ML, Corrado F and Di Benedetto A: Myo-Inositol supplementation and onset of gestational diabetes mellitus in pregnant women with a family history of type 2 diabetes: A prospective, randomized, placebo-controlled study. Diabetes Care 36: 854-857, 2013.

13. Metzger BE, Gabbe SG, Persson B, Buchanan TA, Catalano PA, Damm P, Dyer AR, Leiva A, Hod M, Kitzmiler JL, et al; International Association of Diabetes and Pregnancy Study Groups Consensus Panel: International association of diabetes and pregnancy study groups recommendations on the diagnosis and classification of hyperglycemia in pregnancy. Diabetes Care 33: 676-682, 2010.

14. Plows JF, Budin F, Andersson RA, Mills VJ, Mace K, Davidge ST, Vickers MH, Baker PN, Silva-Zolezzi I and Stanley JL: The effects of myo-inositol and B and D vitamin supplementation in the $\mathrm{db} /$ mouse model of gestational diabetes mellitus. Nutrients 15: pii: E141, 2017.

15. Feig DS and Moses RG: Metformin therapy during pregnancy: Good for the goose and good for the gosling too? Diabetes Care 34: 2329-2330, 2011.

16. Crawford TJ, Crowther CA, Alsweiler J and Brown J: Antenatal dietary supplementation with myo-inositol in women during pregnancy for preventing gestational diabetes. Cochrane Database Syst Rev (12): CD011507, 2015.

17. Corrado F, D'Anna R, Di Vieste G, Giordano D, Pintaudi B, Santamaria A and Di Benedetto A: The effect of myoinositol supplementation on insulin resistance in patients with gestational diabetes. Diabet Med 28: 972-975, 2011.

18. Matarrelli B, Vitacolonna E, D’Angelo M, Pavone G, Mattei PA, Liberati $\mathrm{M}$ and Celentano C: Effect of dietary myo-inositol supplementation in pregnancy on the incidence of maternal gestational diabetes mellitus and fetal outcomes: A randomized controlled trial. J Matern Fetal Neonatal Med 26: 967-972, 2013. 